\title{
Development and Validation of a Questionnaire on Ethical Consumption among a Moroccan Population
}

\author{
Aida Soulaymani ${ }^{1}$, Zakaria Abidli ${ }^{2}$ and Omar Touab ${ }^{1}$ \\ ${ }^{1}$ Research Laboratory in Organizational Management Sciences - National School of Business and \\ Management - Ibn Tofail University - Kenitra, \\ ${ }^{2}$ Laboratory of Genetics and Biometry - Faculty of Science - Ibn Tofail University - Kenitra \\ Morocco
}

\begin{abstract}
According to the literature review, ethics in consumer choice is expressed by consumers. However, the measurement of ethical consumption is still poorly adapted because of its diversified definition in the marketing of consumer behavior. According to the literature review, there is no global scale for measuring ethical consumption behavior in an Arabic-speaking population. For this reason, our objective is to validate a questionnaire on ethical consumption and to determine the profile of this type of consumption among the Moroccan population. A methodological choice is a quantitative approach in which we used a technical sheet with a self-questionnaire and a questionnaire on ethical consumption. The scale validation process is based on two steps. Initially, we calculated the reliability of the entire questionnaire and the three dimensions of the scale by Cronbach's alpha. Exploratory factorial analyses were then carried out. There are 161 participants, 55\% of whom are female compared to $45 \%$ male. The average age of the participants was $41.8 \pm 13.4$ years. For the internal consistency of the questionnaire, we calculated the Cronbach index, which was 0.8 for the whole scale, $\alpha=0.7$ for ethical consumption of textiles, 0.7 for ethical consumption of food and psychoactive substances and $\alpha=0.8$ for the consumption of hygiene, beauty and cosmetic products. consumption of food and psychoactive substances and $\alpha=0.8$ for the consumption of hygiene, beauty and cosmetic products.
\end{abstract}

Key Words: Development, Validation, Questionnaire, Consumption, Ethics, Morocco.

\section{INTRODUCTION}

According to Moingeon, consumption is part of a set of mechanisms that allow individuals to distinguish themselves, particularly through food, cultural and sporting practices [1]. According to the literature review, the majority of disciplines in the social sciences and humanities consider consumption as a social activity before being an individual act [2]. Consumption is an obligation of our lives, because it gives me physiological and psychological stability in daily life. However, several factors can influence consumption, such as social and religious factors. So let's talk about ethical consumption. The literature shows two meanings linking ethics and consumption. On the one hand, the ethics of consumption, which judges the morality of the entire capitalist production system [3]. It is this sense of ethics that prevails in discussions on environmental issues, sustainable consumption and movements such as voluntary simplicity. Consumption is itself the subject of moral evaluation with the objective of controlling or even reducing its overall level [4]. On the other hand, ethical consumption, which considers consumption not as the object of moral evaluation, but as a means of moral and political action. This is the dominant meaning in cases of consumer boycotts, ethical audits, corporate social responsibility actions and fair trade campaigns. Here, ethical consumption does not necessarily imply less consumption [4]. It should be noted that these two meanings of the link between ethics and consumption are not completely opposite. Thus, a succession of ethical consumption campaigns can reduce consumption levels. In the Arabic-speaking context, more particularly in Morocco, the consumption of ethical products such as alcohol and swimwear is one of the taboo subjects in the Moroccan context. To our knowledge, there is no global scale for measuring ethical consumption behaviour in an Arabic-speaking population. For this reason our objective is to validate a questionnaire on ethical consumption and to determine the profile of this type of consumption among the Moroccan population. 


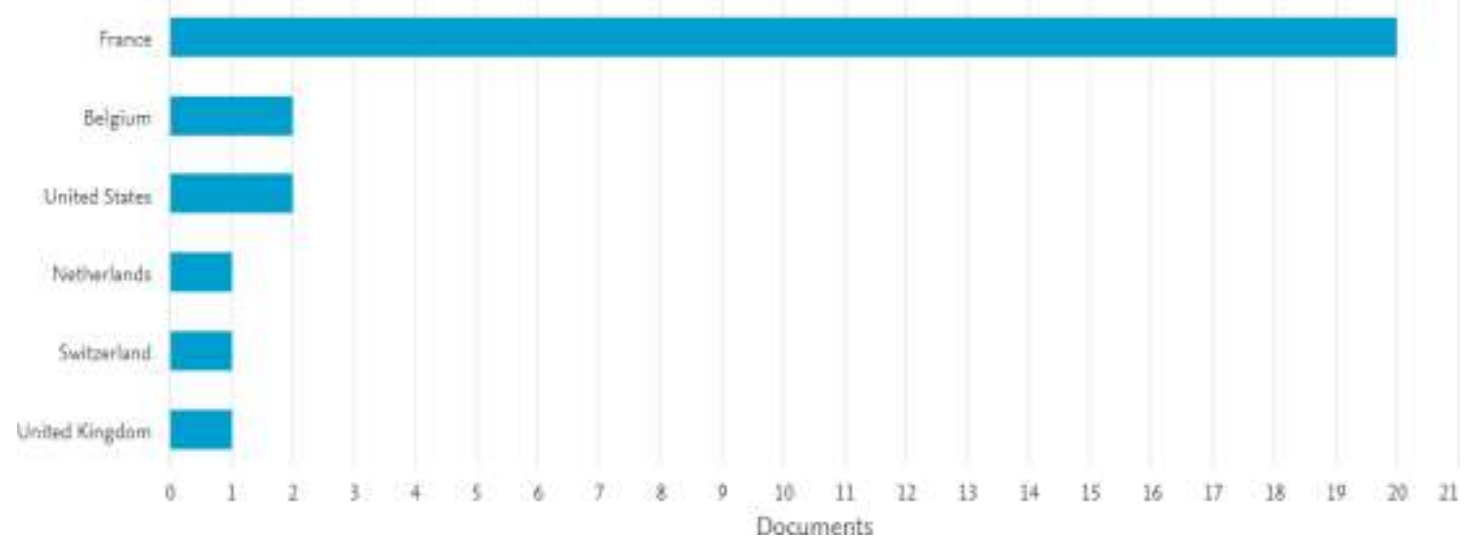

Figure 1.Distribution of published articles on ethical consumption by country (Scopus data)

\section{MATERIALS AND METHODS}

\section{a) Study concept}

To achieve the objectives, have chosen to the quantitative approach as a relevant methodological choice using a valid and reliable questionnaire for measurement and data collection. We used two questionnaires. One is in the form of a self-questionnaire, a questionnaire on ethical consumption..

\section{b) Self-Questionnaire}

We conducted a self-questionnaire on the socio-demographic and professional information of our population.

Questionnaire on ethical consumption.

\section{c) Questionnaire on ethical consumption}

A bibliographical synthesis on ethical consumption has enabled us to select a three-dimensional scale.

The first dimension concerns the ethical consumption of textiles, which contains 27 items; these items are based on the purchase of ethical clothing such as swimwear, nightwear for women and so on. The second dimension concerns the ethical consumption of food and psychoactive substances, which contains 29 items, these items are based on the consumption of meat and drinks prohibited in the Islamic religion.

The third dimension concerns the consumption of hygiene, beauty and cosmetic products, which contains 20 items, the latter have been submitted to the opinions of specialists and professors in economics and biometrics at Ibn Tofail University in Kenitra. The opinion of these experts allowed us to exclude some items.

Table 1.Distribution by questionnaire size

\begin{tabular}{|c|c|c|c|}
\hline Dimensions & $\begin{array}{c}\text { Ethical consumption } \\
\text { textiles }\end{array}$ & $\begin{array}{c}\text { Ethical consumption of food and } \\
\text { psychoactive substances }\end{array}$ & $\begin{array}{c}\text { Consumption of hygiene, } \\
\text { beauty and cosmetic products }\end{array}$ \\
\hline Number of items & 27 & 29 & 20 \\
\hline
\end{tabular}

\section{d) Statistical methodology}

The process of validating the Ethical Consumption Assessment scale is based on two steps. Initially, we calculated the reliability of the entire questionnaire and the three dimensions of the scale by Cronbach's alpha. Exploratory factorial analyses were then carried out (Figure 2). 


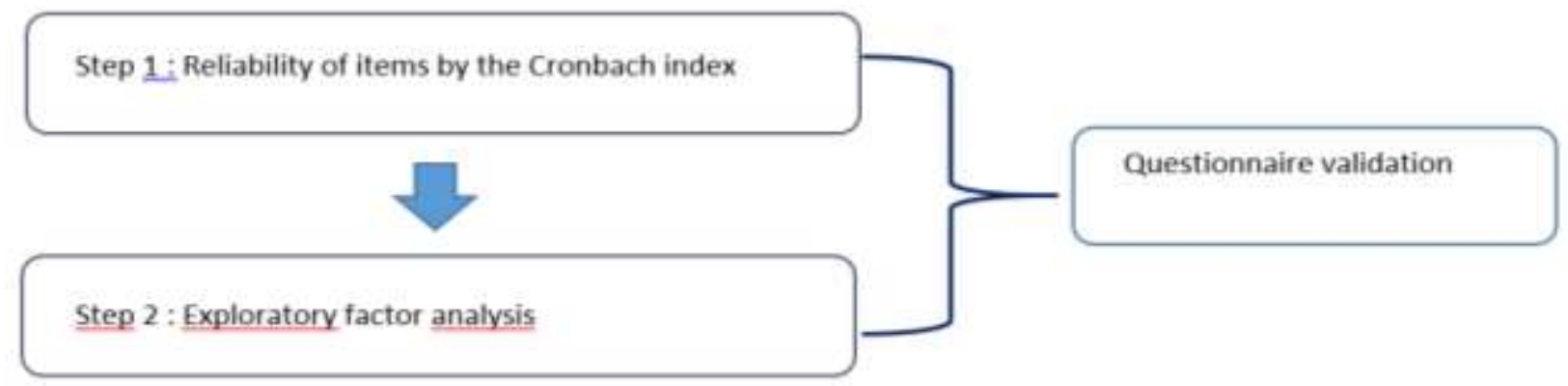

Figure 2. The validation procedures for the questionnaire in our study.

The statistical analyses were carried out by the Statistical Package for the Social Sciences (SPSS) trial version software. The data collected were therefore the subject of exploratory analyses to determine the dimensionality of the scale of the determination of ethical behaviour among a Moroccan population. Principal Component Factor Analysis (PCA) is the most effective method for synthesizing information and discovering the underlying structure of a concept since it is a multi-variate data analysis method that allows simultaneous exploration of the relationships between several variables studied (Field A ,2009) [5]. In our study we used the Kayser Meyer Olkin test (KMO). A KMO score of less than 0.5 is unacceptable, 0.5 is poor, more than 0.6 is acceptable, 0.7 is average, 0.8 is meritorious and 0.9 is excellent studied [6] and Bartlett's sphericity test to assess the potential effectiveness of the PCR studied. For a factor analysis to be feasible, the Bartlett test must be significant $(\mathrm{p}<0.05)$ [10], similarly we calculated the Cronbach alpha to check the reliability and homogeneity between the items on the measurement scale. An alpha between 0.6 and 0.8 is acceptable for an exploratory study [7-9].

\section{RESULTS}

a) Socio-economic and professional characteristics of the study population.

For this study, 161 agreed to participate in this survey, they were 55\% female compared to $45 \%$ male. The average age was 41.8 \pm 13.4 years (Figure 1). Married people accounted for $62 \%$ and single people for $32 \%$. Almost all participants had a university level with a percentage of $93 \%$. In our study population, $79 \%$ of the participants were employees, $47 \%$ of whom had an average financial situation, $36 \%$ had a monthly expenditure greater than $1000 \mathrm{DH}$ and $32 \%$ were unable to manage their budget.

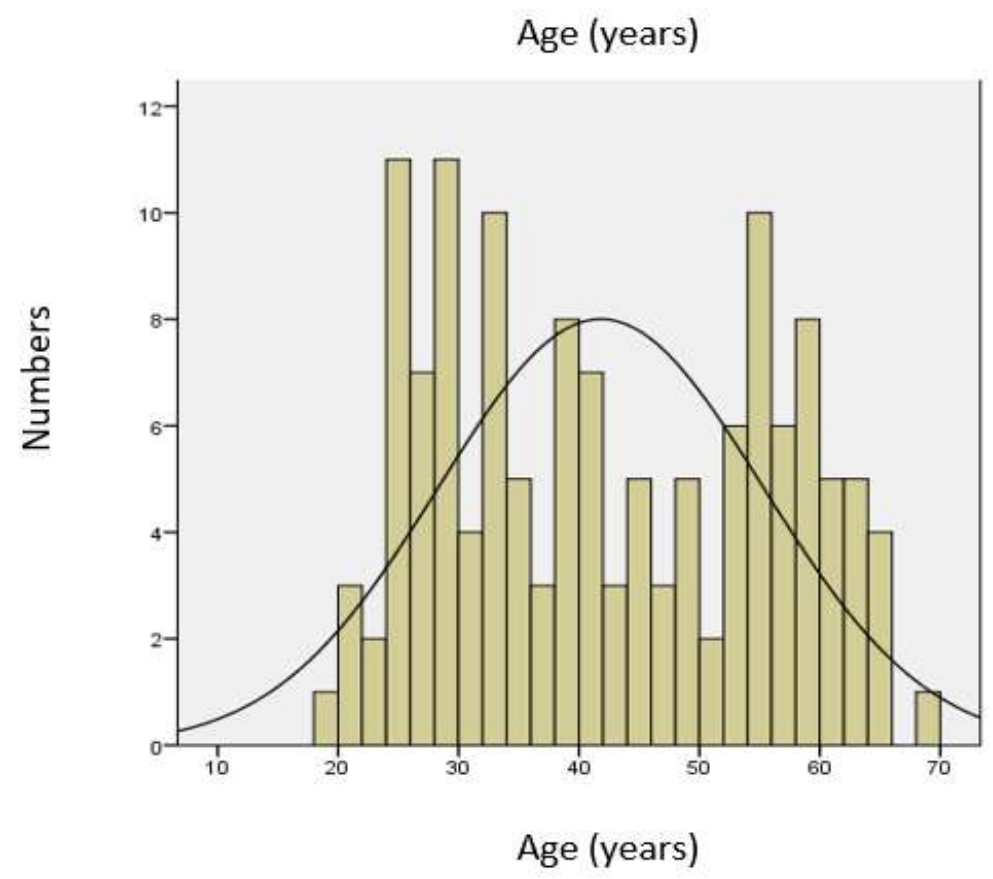

Figure 3.Distribution of participants by age. 


\section{b) Internal reliability of our questionnaire}

For the internal consistency of the questionnaire, we calculated the Cronbach index, which was 0.8 for the whole scale, $\alpha=0.7$ for ethical consumption of textiles, 0.7 for ethical consumption of food and psychoactive substances and $\alpha=0.8$ for consumption of hygiene, beauty and cosmetic products.

Table 2. Distribution of Cronbach's value for each dimension of the questionnaire

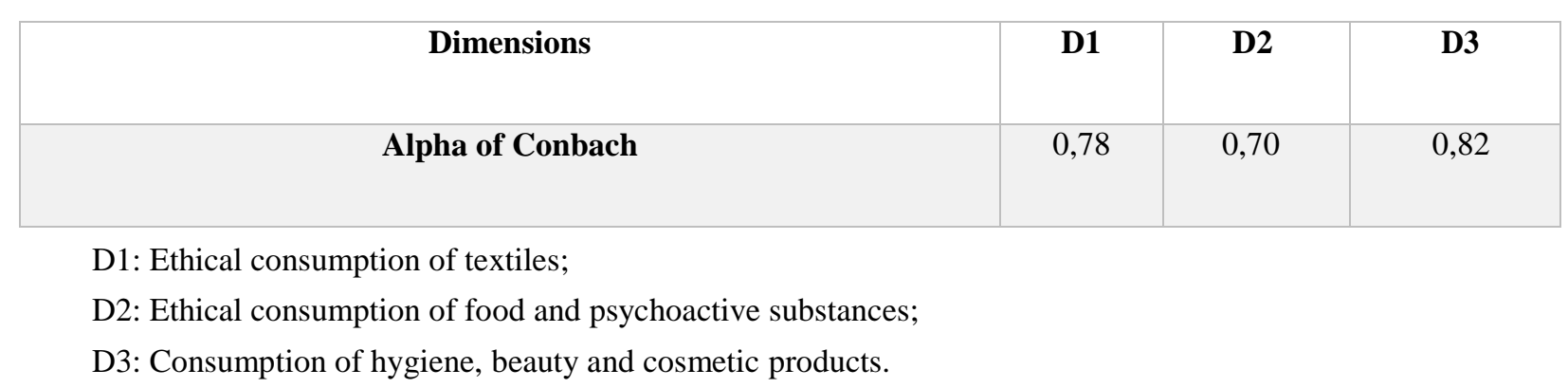

In the light of these results, we can already provide the internal reliability of our questionnaire adapted to the Moroccan context.

\section{c) Factor analysis}

To make a factor analysis of the questionnaire we considered the value of the KMO index and Bartlett's sphericity test. To study the exploratory factor structure of the collected data, we opted for a principal component analysis (PCA), which was carried out with varimax rotation on all the items of the questionnaire. Based on the exploratory factor analysis performed on the selected questionnaire items, the precision measurement result of the Kaiser-Meyer-Oklin (KMO) sampling performed was 0.75 above the critical threshold of 0.6, which allowed factor analysis. Similarly, Bartlett's sphericity test (approximate chi-two = 1007.95; ddl = 120) was highly significant $(\mathrm{p}=0.000)$. The factorial analysis in main axes carried out without constraining the number of factors with varimax rotation revealed three factors whose eigenvalues are greater than 1 and explain $67 \%$ of the total variance. The three dimensions are well defined and distinct on their respective factors; Thus, the first factor, which includes 27 items constituting the dimension of ethical consumption of textiles, explains $32 \%$ of the total variance. The second, with 29 items constituting the dimension of ethical food consumption, explains $30 \%$ of the total variance and the third, with 20 items constituting the consumption of hygiene, beauty and cosmetic products, explains $5 \%$ of the total variance.

The consumption of ethical products is one of the taboo subjects in the Arabic-speaking context, Morocco as an Arab country is no exception. The objective of our study is to validate an instrument for measuring ethical consumption among a Moroccan population. To do the questionnaire validation we followed the Churchill model and on the latest advanced statistical methods in terms of questionnaire validation [10]. Indeed, in the Moroccan context, several studies concerning the validation of the questionnaire are followed this methodology, in several disciplines such as economics, psychology and pharma covigilance [11] [12], [15]. On the psychometric level, our scale is in harmony with a study conducted in France by Jean- François Toti et al in 2015 on measures of ethical behavior [16]. According to the literature review, few studies in economics, such as a study by Muncy and vitelle [17], [16], in 1992 on the scales of ethical consumption, have developed a questionnaire, the most reliable and widely used to date on ethical consumption. The latter have benefited from several empirical studies that have improved it [18], but it remains open to criticism on different levels. In terms of its applicability, some items reflect little of today's reality [16] (Jean- François Toti, 2015). It should also be noted that the scale is limited to relations between customers and sellers and neglects other purchasing decisions, as is the case for the dimensions "actively benefit from illegal activities" and "passive profit" with items such as "give the seller an incorrect price when the label has been removed" or "say nothing when the cashier is wrong in our favour". In 2014, Oh and Yonn limited an instrument to three items to capture ethical consumption intentions. It remains quite abstract and does not measure real or past behaviours, or even preferences, but projects the consumer into a hypothetical future [19]. This wide variety of scales for measuring ethical behaviour makes the boundaries of ethical consumption rather blurred. The others approach it from different angles without really focusing on the concept itself. Our study is the first step in carrying out further studies in the future on ethical consumption, the factors and motivations of this type of consumption. According to the literature review, Consumers are increasingly making consumer choices based on ethical values, social and environmental standards [20], [21]. These consumers are considered to have an ethical meaning. for a wide range of issues such as society, the environment, child labour, pollution, human rights and many other similar concerns [22]. Researchers argue that, by purchasing perceived ethical products (e.g., organic food, fair trade, ecological or ecological products, energy-efficient appliances and 
ecological vehicles) and boycotting unethical products (e.g., products or companies associated with unethical problems), consumers describe their morals and values [20],[22].The researchers proposed different definitions of ethical consumption. To begin, Crane (2004) argued that ethical consumption is a serious and conscious decision related to consumer choices, and that it is motivated by its morality and belief system [23]. Uusitalo et Oksanen [24] have ben describes ethical consumption as a combination of ethical and moral aspects of the production and distribution of different goods. Experts insist that ethical consumption is a global concept, as it encompasses all types of consumption, such as green consumption, sustainable, socially responsible and similar types of consumption [25]. Thus, ethical consumption mainly involves the purchase of perceived ethical products (e. g. organic or energy-efficient appliances) or the support of ethical practices (e. g. recycling, fair trade) by companies. Many researchers have tried to study the relationship between ethics and organic food. However, to the best of our understanding, there are few publications on the influence of barriers on ethical consumption intent in the context of organic food.

\section{CONCLUSION}

In the light of these results, we can already provide the internal reliability of our questionnaire adapted to the Moroccan context and we can therefore evaluate the behaviour of ethical consumption using a valid and reliable questionnaire in the Moroccan context.

\section{REFERENCE}

1]: Moingeon B, The sociology of Pierre Bourdieu and his contribution to marketing, Research and Applications in Marketing, vol. 8 , no. 2, p. 105-123, 1993.

[2]: Darpy D, Consumer Behaviours, Concepts and Tools, Paris, Dunod.2012.

[3]: Crocker D. A., Linden T, Ethics of Consumption: Introduction, Ethics of consumption: The good life, justice, and global stewardship, Philosophy and the Global Context series- Lanham, Md. and Oxford, Rowman and Littlefield,1998.

[4]: Barnett C., Cafaro P., Newholm T, Philosophy and ethical consumption, in Harrison R., Newholm T., Shaw D., Ed., The ethical consumer, London, Sage, p.138-153,2005.

[5]: Field A, Discovering statistics using SPSS, 3rd ed. Third edition, editors, New York: SAGE Publications, 2009.

[6]: Stewart DW. The Application and Misapplication of Factor Analysis in Marketing Research, J Mark Res, 18(1):51 -62, 1981.

[7]: DMSP. Research Centre. The proposition of a contextualized scale of measurement team learning: An Exploratory Analysis. Université de Paris-Dauphine, Paris, France. 2003. [cited $10 \mathrm{~S}$ Septembre 2019], Available from:

https://basepub.dauphine.fr/ bitstream/handle/123456789/4299/CR321.pdf\%3Bsequence\%3D1.

[8]: Johnson RA, Wichern DW. Applied Multivariate Correspondence Analysis. 6th edition. Prentice-Hall, editors. USA: Upper Saddle River, NJ, 2007.

[9]: Yves E, Pras B, Roux E. Market-Etudes et Recherches en marketing. 2nd ed.Dunod, editors. France: Gestion Sup. 2003.

[10]: Churchill GA. A Paradigm for Developing Better Measures of Marketing Constructs. J Mark Res, 16(1):64-73, 32 , 1979.

[11] : Fabrigar LR, Wegener DT, MacCallum RC, Strahan EJ. Evaluating the use of exploratory factor analysis in psychological research. Psychol Methods. 1999;4(3):272-99. 33.

[12] Campoy E, Durrieu F, Roussel P, Akremi AE. Structural equation methods: Research and applications in management. Economica, editors. Paris: Economica. 2002;1:303-46.

[13] Harzy T, Nejjari C, Serhier Z, N. Akasbi, Guillemin F, Bono Adaptation et validation d'une version marocain du questionnaire arthrose des membres inférieurs et qualité de vie chez des patients atteints de gonarthrosis et de coxarthrosis, Revue d'Epidémiologie et de Santé Publique, 56 ;S2 :94, 2008. 
[14] :Ben Hanana E, Houfaidi S, Satisfaction du personnel: validation d'une échelle de Mesure dans le contexte des administrations publiques Marocaines, International Journal of Innovation and Applied Studies, 18:056-1073,2016.

[15] :Abidli Z, Jadda S, Ammor S, Soulaymani A, Mokhtari A, Soulaymani-Bencheikh R, Hami H, Development and Validation of a Questionnaire on Pharmacovigilance Knowledge among Health Professionals in Morocco, 11(4): 391-39,2019.

[16]: Jean-François T, Jean-Louis M, Comment mesurer les comportements de consommation éthique, Revue Interdisciplinaire Management, Homme \& Entreprise,18:2 -42,2015.

[17]: Muncy J.A., Vitell S.J, Consumer Ethics : an investigation of the ethical beliefs of the final consumer, Journal of Business Research, 24:297-311,1992.

[18]: Vitell S.J., Muncy J, The Muncy-Vitell consumer ethics scale : A modification and application, Journal of Business Ethics, $62 ; 267-278,2005$.

[19]: Oh J-C., Yoon S-J, Theory-based approach to factors affecting ethical consumption, International Journal of Consumers Studies, 38:278-288, 201

[20]: Coelho SL, Fairtrade consumers in Portugal: values and lifestyles, International Journal of Consumer Studies, 39:437-444, 2015.

[21]: Ladhari R,Michèle Tchetgna N, Values, socially conscious behaviour and consumption emotions as predictors of Canadians' intent to buy fair trade products, International journal of constitutional, 41;(6):696-705,2017.

[22]: Michal J. Carrington Benjamin A. Neville Gregory J. Whitwell, Why Ethical Consumers Don't Walk Their Talk: Towards a Framework for Understanding the Gap Between the Ethical Purchase Intentions and Actual Buying, Behaviour of Ethically Minded Consumers, Journal of Business Ethics,97:139-158,2010.

[23]: Crane, A. D. Matten, Business Ethics: A European Perspective (Oxford University Press, Oxford), 2004.

[24]: Uusitalo O., Oksanen R., Ethical consumerism: a view from Finland, International Journal of Consumer Studies, 28:214221,2004 .

[25]: Carrigan,M, A.Attalla,'TheMythoftheEthical Consumer -DoEthicsMatter in purchase Behaviour?, Journal of Consumer Marketing 18(7), 560-577,2001. 